\title{
Attitudes towards body weight dissatisfaction associated with adolescents' perceived health and sleep (PeNSE 2015)
}

\author{
Insatisfação e atitudes relativas ao peso corporal associada à \\ percepção de saúde e ao sono em adolescentes (PeNSE 2015)
}

Thiago de Sousa Matias (https://orcid.org/0000-0003-0241-3776) ${ }^{1}$

Kelly Samara da Silva (https://orcid.org/0000-0002-7356-1680) ${ }^{1}$

Giovani Firpo Del Duca (https://orcid.org/0000-0003-0893-2032) ${ }^{1}$

Cecília Bertuol (https://orcid.org/0000-0003-1277-775X) ${ }^{1}$

Marcus Vinicius Veber Lopes (https://orcid.org/0000-0002-7968-5211) ${ }^{1}$

Markus Vinícius Nahas (https://orcid.org/0000-0002-4378-4031) ${ }^{1}$
${ }^{1}$ Educação Física, Universidade Federal de Santa Catarina. R. Eng. Agronômico Andrei Cristian Ferreira s/n Trindade. 88040-900 Florianópolis SC Brazil. thiagosousamatias@ gmail.com

\begin{abstract}
This study aimed to investigate whether attitudes towards body weight dissatisfaction is associated with perceived health and impairments in sleep among a national population-based sample of Brazilian adolescents. This is a cross-sectional data from the 2015 National School-Based Health Survey (PeNSE). A total of 100.182 students $(70.8 \%$ were between 14 to 15$)$ in ninthgrade, enrolled in public and private schools were eligible for data analysis. Variables were measured using a questionnaire and binary logistic regression was used. There was association between attitudes towards body weight dissatisfaction and perceived health (not controlling weight $=O R$ : 2.19, 95\% CI: 2.00-2.40; trying to lose $=$ OR: 1.90, 95\%CI: 1.75-2.05; gain = OR: 2.22, 95\%CI: 2.01 2.46; maintain $=$ OR: $1.81,95 \%$ CI: 1.54-2.14). Adolescents were also more likely to present impairments in sleep (not controlling weight $=O R$ : 1.21, 95\%CI: 1.11-1.32; trying to lose = OR: 1.16, 95\%CI: $1.08-1.25$; gain = OR: 1.43 , 95\%CI: 1.28 1.61; maintain $=$ OR: $1.43,95 \%$ CI: $1.22-2.68$ ). Dissatisfaction is an additional concern in the daily life of adolescents, which is associated to depreciation of the quality of sleep and decrement of psychological well-being.
\end{abstract}

Key words Body Image, Adolescent, Mental Health, Sleep, Cross-Sectional Studies
Resumo Este estudo teve como objetivo investigar se as atitudes em relação à insatisfação com o peso corporal (PC) estão associadas à saúde percebida e ao comprometimento do sono em uma amostra de base populacional de estudantes brasileiros. A Pesquisa Nacional de Saúde do Escolar possui delineamento transversal e foram elegiveis para as análises 100.182 estudantes do nono ano. Foi utilizado regressão logística binária para analisar a associação entre as variáveis investigadas, obtidas por meio de questionário. Houve associação entre as atitudes em relação à insatisfação com o PC e a saúde percebida, indicando que aqueles insatisfeitos com o PC apresentaram maior OR para a percepção negativa de saúde (não controlando $o$ peso $=$ OR: 2,19, IC95\%:2,00-2,40, tentando perder $=$ OR: 1,90, IC95\%: 1,75-2,05; ganhar $=$ OR: 2,22, IC95\%: 2,01-2,46; manter $=$ OR: 1,81, IC95\%: 1,54-2,14) e para o comprometimento do sono (não controlando o peso = OR: 1,21, IC95\%: 1,11-1,32; tentando perder $=$ OR: 1,16, IC95\%: 1,08-1,25; ganhar $=$ OR: 1,43,95\% CI: 1,28-1,61; manter $=$ OR: 1,43, IC95\%: 1,22-1,68) em relação àqueles satisfeitos com o PC. A insatisfação é uma preocupação adicional na vida diária dos adolescentes, que está associada à depreciação da qualidade do sono e à diminuição do bem-estar psicológico.

Palavras-chave Imagem Corporal, Adolescente, Saúde Mental, Sono, Estudos Transversais 


\section{Introduction}

Adolescence is characterized by a period in which many changes occur, considering that the person undergoes many biological and psychosocial adjustments, such as alterations in body proportion and body image distortion ${ }^{1,2}$. As a consequence, an increase in the levels of stress and reduced sleep quality due to poor psychological status is observed $^{3-6}$.

Psychological health-related difficulties have been observed in the literature as a consequence of the exposure to a set of psychological concerns, such as body dissatisfaction ${ }^{7}$. It is observed that adolescents experience high levels of dissatisfaction with body weight ${ }^{1,8}$, signaling important health risks for this population?.

Body dissatisfaction seems to be common and persistent and imposes health-related risks to both genders ${ }^{4,5,10}$. The emphasis on physical appearance and the way that the individual visualizes his or her own weight (negative perception) is associated with psychological concerns ${ }^{7}$. This negative perception appears as the adolescent is non-compliant to socially valued beauty standards, which results in maladaptive outcomes $^{1,11}$. On the other hand, it is observed that these concerns do not seem to represent motivational incentives to adopt positive health behaviors in daily life; rather, it is suggested that high levels of dissatisfaction are related to poorer health status ${ }^{12,13}$, such as impaired sleep ${ }^{3,14}$.

Although the lack of evidence of this relationship, it is considered that in adolescence, body dissatisfaction reverberates with high degrees of psychological activation, impairing the quality of sleep ${ }^{3,6}$. It is suggested that social exposure to models of "ideal bodies" further adds concerns among adolescents, thus impairing sleep ${ }^{15,16}$.

Therefore, identifying adolescents' exposure factors that detract psychological health constitutes an important public health strategy. It is important to consider that body weight dissatisfaction in adolescence manifests itself in the sense of different attitudes towards as wanting to lose or increase body weight ${ }^{1,2,8,17}$. However, associations between body weight dissatisfaction and psychological variables have been broadly evaluated without considering these factors ${ }^{5,18}$.

It is important to consider the current demands for investigations on the health-related risks for body weight dissatisfaction by increasing weight, considering that this has been underexplored in the literature ${ }^{5}$. Specifically, the present study aimed to investigate whether attitudes towards body weight dissatisfaction is associated with perceived health, and impairments in sleep among a national population-based sample of Brazilian adolescents.

\section{Methods}

\section{Design and Participants}

The survey "National School-based Health Survey (PeNSE)" presents national wide and school-based epidemiological characteristics with a repeated cross-sectional delimitation. The study is part of the Brazilian Surveillance of Risk and Protection Factors for Chronic Diseases and was developed according to the World Health Organization (WHO) recommendations. The study has been conducted with a partnership between Health Surveillance Secretariat of the Brazilian Ministry of Health, WHO, the Pan-American Health Organization (PAHO) and the Centers for Disease Control and Prevention of the United States (CDC/USA), which allows broader comparability with international surveys.

The PeNSE study aims to fill the gaps on the knowledge about the health situation of Brazilian adolescents and to comply with WHO recommendations. The survey is realized by the Ministry of Health and the Institute of Geographic and Statistics (IBGE) with support of the Ministry of Education (MEC). Its planning began in 2004 with its first wave collected in 2009 ( $\mathrm{n}=$ 63,411), the second in $2012(\mathrm{n}=109,104)$ and the third and most recent in 2015. This last edition included two samples, the first one composed by ninth-grade students $(\mathrm{n}=102,301)$ and the second one by high school students $(\mathrm{n}=10,926)$. In this study, data from the first sample (ninthgrade students) of 2015 were evaluated. The project was approved by the National Research Ethics Committee, in compliance to the National Health Council (CNS) and all the data collection procedures were conducted according with ethical guidelines.

The study's sample was composed by students from public and private schools located in urban and rural areas of the Brazilian territory. The sample size was estimated considering the 26 state capitals, and the federal district, distributed in the five Brazilian macroregions. The 2013 School Census database was used as the sampling framework and multi-stage cluster sampling procedures were applied. The sample size was defined considering $50 \%$ estimated prevalence, 
thus taking on the maximum variance of the sample estimators, a confidence interval of $95 \%$ and a maximum error of three percentage points. The final stratification included 53 geographical strata, 27 representing the capitals and the federal district and 26 representing other municipalities from each Brazilian state, excluding capitals. The selection of the sample units was conducted in two stages: (1) schools stratified by dependency units (public and private) and sizes $(\leq 2$ ninth year classes; $>2$ ninth year classes); and (2) classes. Further information on the methods can be verified in previously published study ${ }^{19}$.

\section{Measurements}

Adolescents answered to a questionnaire using smartphones while in the classroom. The amount of time needed to complete the questionnaire was approximately 40 minutes. The instrument was build based on standardized questionnaires (e.g. Global School-Based Student Health Survey - GSHS ${ }^{20}$ and Youth Risk Behavior Surveillance System - YRBS ${ }^{21}$ ) that were previously adapted for Brazilian adolescents ${ }^{22}$. Training courses, applied to interviewers, were conducted in each federative unit to ensure the quality and standardization of the procedures for data collection. The questions to evaluate the variables "perceived health" and "impairments in sleep" were adapted from the GSHS questionnaire. The original question regarding "attitude towards body weight" was available in both GSHS and YRBS questionnaires. The variable "body weight dissatisfaction" was obtained by a question validated for Brazilian adolescents in the COMPAC study ${ }^{23}$.

Perceived health was investigated using a health self-assessment scale dichotomized as "positive" ("very good" and "good") and "negative" (for "regular", "bad" and "very bad"). Impairments in sleep was assessed by the following question: "How often were you unable to sleep at night because something really bothered you?" and categorized as "yes" ("sometimes", "mostly" and "always") and "no" ("never" and "rarely"). Body weight dissatisfaction was evaluated by a self-assessment scale and dichotomized as "satisfied" and "dissatisfied". Finally, attitude towards body weight was assessed by the question "What are you doing in relation to your body weight?" with the following answers "doing nothing", "trying to lose weight", "trying to gain weight" and "trying to maintain weight". The variables body weight dissatisfaction and attitude towards body weight were combined to be analyzed as "satisfied" (regardless of the attitude towards body weight), "dissatisfied and not controlling weight", "dissatisfied and trying to lose weight", "dissatisfied and trying to gain weight" and "dissatisfied and trying to maintain weight". The variables "perceived health" and "impairments in sleep" were evaluated as outcomes and the combination between "body dissatisfaction" and "attitude towards body weight" as exposure.

\section{Statistical Analysis}

The data were analyzed using Stata SE, version 13.0 (Stata Inc., College Station, TX, USA). In all the statistical procedures, the methodology for complex analysis and weighting was used to incorporate strata, conglomerates, and sample weight. Observations with missing data in at least one variable of interest were excluded from the analyses. Descriptive statistics (absolute and relative frequency) were used to characterize the sample according to the exposures and outcomes. Binary logistic regression (crude and adjusted) was used, with values expressed in Odds Ratio (OR) and their respective 95\% confidence intervals $(95 \% \mathrm{CI})$ to verify the association between the combination of body dissatisfaction and attitude towards body weight with health-related outcomes. The regression analyses were adjusted by gender, age, mother's schooling, ethnicity, occupational status (model 1) and loneliness (model 2) and a full model was also considerate (model 3). Since the survey did not included a depression measure, which is evidenced as a strong predictor of mental health, the variable loneliness was included in adjustments. Recent evidences observed significant association between body dissatisfaction and emotional ill-being (sadness and loneliness) among adolescent; it was observed that the final stages of elementary school are a period of intense physical and emotional changes due to many social expectations, which in turns expose adolescents to risk of sadness and loneliness, particularly related to body dissatisfaction ${ }^{24}$.

In order to correct for multiple testing, the Bonferroni correction was applied (significance level $=\alpha / n$ - were $\alpha$ is the $p$-value 0.05 and $n$ is the number of associations being tested, in our case, $n=5$ ). Therefore, we considered as statistically significant any association with $\mathrm{p}$-value $<$ $0.01)$. 


\section{Results}

A total of 100.182 adolescents (51.7\% girls) of whom $70.8 \%$ were between 14 to 15 years old answered to all the investigated questions and were analyzed. Regarding the distribution of the outcome and exposure variables (Table 1), 27.0\% of the adolescents negatively perceived their health, $36,2 \%$ reported impairments in sleep, $28.0 \%$ were dissatisfied with their body and approximately $60 \%$ were trying to lose, gain or maintain their body weight. When both variables, body weight dissatisfaction and attitude towards body weight, were combined, it was observed that $12.6 \%, 5.1 \%$ and $2.4 \%$ of adolescents were simultaneously dissatisfied with their body and trying to lose, gain or maintain their weight, respectively.

The association between attitude towards body weight dissatisfaction and adolescent's perceived health was showed in Table 2. After adjustment (model 3), those who were dissatisfied with their body but were not controlling their weight had 2.19 times higher odds (95\%CI: 2.00-2.40) of perceiving their health as negative when compared to adolescents satisfied with their body. Those who were dissatisfied and were trying to lose or gain weight had 1.90 (95\%CI: 1.75-2.05) and 2.22 (95\%CI: 2.01-2.46) odds respectively. In addition, adolescents dissatisfied who were trying to maintain their weight had 1.81 (95\%CI: 1.54-2.14) times higher odds to perceive their health negatively when compared to adolescents satisfied with their body weight.

When sleep impairments were analyzed ( $\mathrm{Ta}-$ ble 3), it was also observed associations with body weight dissatisfaction. Adolescents who were dissatisfied and were not controlling their weight were 1.21 (95\%CI: 1.11-1.32) more likely to present impairments in sleep in relation to adolescents satisfied with their weight. Those who were dissatisfied and were trying to lose (OR: 1.16, 95\%CI: 1.08-1.25) and gain (OR: 1.43, 95\%CI: 1.28-1.61) weight had also higher odds. And those who were dissatisfied and were trying to maintain their weight presented 1.43 odds of having sleep impairments.

\section{Discussion}

The present study aimed to investigate whether attitudes towards body weight dissatisfaction is associated with perceived health, and impairments in sleep among Brazilian adolescents. Body weight dissatisfaction was associated with
Table 1. Proportions and confidence intervals of adolescent's perceived health, impairments in sleep, body satisfaction and attitudes towards body weight ( $\mathrm{n}=100,182)$. Brazil, 2015.

\begin{tabular}{|c|c|c|}
\hline Variables & $\%^{*}$ & CI95\% \\
\hline \multicolumn{3}{|l|}{ Perceived health } \\
\hline Positive & 73.03 & $(72.48 ; 73.57)$ \\
\hline Negative & 26.97 & $(26.43 ; 27.52)$ \\
\hline \multicolumn{3}{|l|}{ Impaired sleep } \\
\hline No & 63.82 & $(63.19 ; 64.44)$ \\
\hline Yes & 36.18 & $(35.56 ; 36.81)$ \\
\hline \multicolumn{3}{|l|}{ Body satisfaction } \\
\hline Satisfied & 72.05 & $(71.44 ; 72.65)$ \\
\hline Dissatisfied & 27.95 & $(27.35 ; 28.56)$ \\
\hline \multicolumn{3}{|l|}{$\begin{array}{l}\text { Attitude towards body } \\
\text { weight }\end{array}$} \\
\hline Not controlling & 39.31 & $(38.71 ; 39.92)$ \\
\hline Trying to lose & 25.64 & $(25.07 ; 26.21)$ \\
\hline Trying to gain & 16.26 & $(15.82 ; 16.70)$ \\
\hline Trying to maintain & 18.79 & $(18.34 ; 19.25)$ \\
\hline \multicolumn{3}{|l|}{$\begin{array}{l}\text { Body satisfaction and } \\
\text { attitude combined }\end{array}$} \\
\hline Satisfied & 72.05 & $(71.44 ; 72.65)$ \\
\hline $\begin{array}{l}\text { Dissatisfied and not } \\
\text { controlling weight }\end{array}$ & 7.84 & $(7.52 ; 8.18)$ \\
\hline $\begin{array}{l}\text { Dissatisfied and trying } \\
\text { to lose weight }\end{array}$ & 12.56 & $(12.12 ; 13.01)$ \\
\hline $\begin{array}{l}\text { Dissatisfied and trying } \\
\text { to gain weight }\end{array}$ & 5.11 & $(4.85 ; 5.39)$ \\
\hline $\begin{array}{l}\text { Dissatisfied and trying } \\
\text { to maintain weight }\end{array}$ & 2.43 & $(2.26 ; 2.62)$ \\
\hline
\end{tabular}

Note: ${ }^{\star}$ Weighted proportions.

a negative perceived health. This association has been confirmed in previous literature and longitudinal studies have pointed out that, besides not serving as an incentive for the adoption of healthy-related behaviors, dissatisfaction is related to a decrease in the general health status ${ }^{12,13}$, exposing adolescents to risks for eating disorders ${ }^{10}$. The risks are evidenced in some studies demonstrating the relationship between psychological well-being and weight dissatisfaction ${ }^{4,5}$. It is observed that during adolescence, body weight dissatisfaction is predictive of psychological concerns, such as low self-esteem, stress, depression, loneliness and sadness $\mathbf{s}^{5,24,25}$.

It is important to notice that the role of adolescence imposes to individual many social pressures regarding body dissatisfaction. The body 
Table 2. Adolescents' attitudes towards body weight dissatisfaction associated with perceived health $(\mathrm{n}=$ 100,182). Brazil, 2015.

\begin{tabular}{|c|c|c|c|c|c|c|c|c|}
\hline \multirow{2}{*}{ Variables } & \multicolumn{2}{|r|}{ Crude } & \multicolumn{2}{|c|}{ Model $1^{\mathrm{a}}$} & \multicolumn{2}{|c|}{ Model $2^{\text {b }}$} & \multicolumn{2}{|c|}{ Model $3^{c}$} \\
\hline & OR $^{\star}$ & IC95\% & OR $^{\star}$ & IC95\% & OR $^{*}$ & IC95\% & $\mathrm{OR}^{*}$ & IC95\% \\
\hline \multicolumn{9}{|l|}{$\begin{array}{l}\text { Body satisfaction and attitude } \\
\text { combined }\end{array}$} \\
\hline Body satisfaction & 1.00 & & 1.00 & & 1.00 & & 1.00 & \\
\hline $\begin{array}{l}\text { Body dissatisfaction (not } \\
\text { controlling) }\end{array}$ & 2.64 & $(2.42 ; 2.88)$ & 2.63 & $(2.41 ; 2.87)$ & 2.13 & $(1.95 ; 2.33)$ & 2.19 & $(2.00 ; 2.40)$ \\
\hline Body dissatisfaction (lose) & 2.27 & $(2.11 ; 2.45)$ & 2.26 & $(2.09 ; 2.44)$ & 1.83 & $(1.69 ; 1.98)$ & 1.90 & $(1.75 ; 2.05)$ \\
\hline Body dissatisfaction (gain) & 2.74 & $(2.49 ; 3.01)$ & 2.68 & $(2.44 ; 2.95)$ & 2.2 & $(1.99 ; 2.43)$ & 2.22 & $(2.01 ; 2.46)$ \\
\hline $\begin{array}{l}\text { Body dissatisfaction } \\
\text { (maintain) }\end{array}$ & 2.07 & $(1.77 ; 2.43)$ & 2.11 & $(1.80 ; 2.48)$ & 1.75 & $(1.49 ; 2.06)$ & 1.81 & $(1.54 ; 2.14)$ \\
\hline
\end{tabular}

Table 3. Adolescents' attitudes towards body weight dissatisfaction associated with impairments in sleep $(\mathrm{n}=$ 100,182). Brazil, 2015.

\begin{tabular}{|c|c|c|c|c|c|c|c|c|}
\hline \multirow{2}{*}{ Variables } & \multicolumn{2}{|r|}{ Crude } & \multicolumn{2}{|c|}{ Model $1^{\mathrm{a}}$} & \multicolumn{2}{|c|}{ Model $2^{\text {b }}$} & \multicolumn{2}{|c|}{ Model 3c } \\
\hline & OR $^{*}$ & IC95\% & $\mathrm{OR}^{\star}$ & IC95\% & $\mathrm{OR}^{*}$ & IC95\% & $\mathrm{OR}^{*}$ & IC95\% \\
\hline \multicolumn{9}{|l|}{$\begin{array}{l}\text { Body satisfaction and attitude } \\
\text { combined }\end{array}$} \\
\hline Body satisfaction & 1.00 & & 1.00 & & 1.00 & & 1.00 & \\
\hline $\begin{array}{l}\text { Body dissatisfaction (not } \\
\text { controlling) }\end{array}$ & 1.89 & $(1.73 ; 2.07)$ & 1.8 & $(1.64 ; 1.97)$ & 1.21 & $(1.11 ; 1.32)$ & 1.21 & $(1.11 ; 1.32)$ \\
\hline Body dissatisfaction (lose) & 1.84 & $(1.73 ; 1.97)$ & 1.7 & $(1.59 ; 1.82)$ & 1.18 & $(1.09 ; 1.27)$ & 1.16 & $(1.08 ; 1.25)$ \\
\hline Body dissatisfaction (gain) & 2.24 & $(2.00 ; 2.50)$ & 2.15 & $(1.92 ; 2.40)$ & 1.42 & $(1.27 ; 1.60)$ & 1.43 & $(1.28 ; 1.61)$ \\
\hline Body dissatisfaction (maintain) & 1.93 & $(1.66 ; 2.24)$ & 1.95 & $(1.68 ; 2.27)$ & 1.39 & $(1.18 ; 1.62)$ & 1.43 & $(1.22 ; 1.68)$ \\
\hline
\end{tabular}

image concerns are related to socio-cultural expectations of appearance which in turns added additional apprehensions in adolescents' daily $\operatorname{life}^{7,15}$. In this sense, body dissatisfaction is a result of the incoherence between what the adolescent really is and what he wants to be ${ }^{15,16}$. In this way, recent literature suggested that there is a need to be coherent in adolescence in order to decrease sources of stress such as body dissatisfaction and having a better psychological well-being; it was observed from the results that a higher sense of coherence was significantly associated with lower scores on all measures of body dissatisfaction such as drive for thinness, body shape concerns, self-depreciation due to physical appearance and the cognitive experience of feeling fat ${ }^{26}$.

These findings help to better understand our pattern of results. Beyond the sources of dissatisfaction, which is all associated to a negative perceived health, it is suggested that avoid incoher- ence is fundamental for overall functioning and general well-being. It seems that the extent to be harmful will be associated to the adolescents' coping strategy to avoid social stressors related to appearance, requiring a great level of resilience engendered by coherence ${ }^{26}$.

Despite observing risks for all groups of attitudes towards body weight, our findings revealed that the difference between the sources of attitudes is not great. A longitudinal study of 2,139 adolescents identified that boys who had an average weight, but perceived themselves as overweight or underweight, had significantly more depressive symptoms compared to those without body image distortion ${ }^{4}$. This means that the risk to mental health is independent of the reasons of the dissatisfaction. Richard et al.'s ${ }^{5}$ study with nearly 16,000 participants, established a positive association between body dissatisfaction and depression independent of multiple factors in- 
cluding body mass index (BMI). Richard et al.' $\mathrm{s}^{5}$ also discussed the importance of evaluating both dissatisfactions, related to losing and gaining weight, considering the current social demands to strong bodies.

Our pattern of results demonstrating different attitudes regarding attempts to change body weight is suggestive that the BMI may not play a significant role in the association between body dissatisfaction and psychological health. Indeed, evidences from a recent longitudinal study (two independent cohorts that were first assessed in early/middle adolescence, reassessed at 5 and 10-year follow-up) observed that the temporal association between body dissatisfaction and depressive symptoms was shown to be independent of changes in BMI for girls. Among boys did not attenuate any of the body dissatisfaction-driven pathways. However, BMI decreased the relationship for females and a reverse relationship appears for male. The research is evocative that the binomial BMI/body dissatisfaction still a matter to debate as dissatisfaction presented an overall negative impact on health and well-being ${ }^{27}$.

It was also observed that in all condition of dissatisfaction, the adolescents self-evaluated with poor sleep quality compared to adolescents satisfied with their body weight. There are indications that the set of distortions of body image, such as dissatisfaction with weight, influences other components of health, among which sleep is included. The hypotheses of this relationship were analyzed by Arigo and Smyth ${ }^{3}$, who draw attention to two constant problems in the youth: student: 1) academic pressures and 2) concerns about the body, variables related to stress, and difficulties with sleep. In the same study, the effect of an expressive writing intervention based on the concerns with the body was observed in reducing health related problems, such as difficulty with sleeping. Given the positive results of the intervention, it was warned that body concerns represent stress factors that interfere with sleep quality ${ }^{3}$. It is suggested that the stressor induces a ruminative thinking process, increasing cognitive activation and impairing sleep as a consequence ${ }^{6}$.

It seems that the negative implications of body weight dissatisfaction on sleep impairments are established in an indirect way; a perception of dissatisfaction is driven by emotional depre- ciation, such as stress. Studies have observed that stress is detrimental to sleep quality ${ }^{28,29}$. Physiologically, the increased cortisol concentration in the bloodstream, in response to stress, results in the difficulty in falling asleep and sustaining uninterrupted sleep. This is due to the suppressive effect of Rapid Eye Movement sleep, characteristic of the hormone $e^{30}$.

In the present study, some limitations are addressed. The outcomes are based on self-reported measures and the biases that accompany cross-sectional self-reported studies are well known; however, the sample was composed of a representative number of adolescent students from Brazil, a middle-income country, which is scarce in literature. Our possibility to generalize these findings to other health-related outcomes is limited, and further research is required to encompass the diversity of important variables such as depression. It is also important to consider that, despite evaluating a unidirectional relationship between the investigated variables, it is possible that important mediators such stress and BMI may influences the relationships between body weight dissatisfaction and health-related outcomes, in this sense stress and BMI (PeNSE 2015 sample 1 survey design was not able to properly collect weight and height information) were not investigated in the present study. Also, the relationship between body dissatisfaction and perceived health can occur in a reverse way. We also point out some strengths, the present study was conducted by analyzing the different attitudes towards body weight dissatisfaction, observing which behaviors, regardless the attitude, negatively predicted health status. Further investigation should explore more the differences related to body dissatisfaction attitudes taking into consideration the BMI.

\section{Conclusions}

Body weight dissatisfaction is related to a negative perceived health, and impairments in sleep. The risk is established in all groups of adolescents with attitudes towards body weight dissatisfaction. It was observed that dissatisfaction is an additional concern in the daily life of adolescents, which may consequently lead to the depreciation of psychological well-being. 


\section{Collaborations}

TS Matias conceived and were responsible for the design and overall direction of this study; drafted the manuscript; critically revised the manuscript. C Bertuol conceived and were responsible for the design and overall direction of this study; performed statistical analyses and contributed to the interpretation of the results; drafted the manuscript. MVV Lopes conceived and were responsible for the design and overall direction of this study; performed statistical analyses and contributed to the interpretation of the results; drafted the manuscript. KS Silva were involved in interpretation of the results; critically revised the manuscript. GF Del Duca were involved in interpretation of the results; critically revised the manuscript. MV Nahas critically revised the manuscript. All authors read and approved the final manuscript.

\section{Acknowledgment}

The authors would like to thank the Ministry of Health and the Institute of Geographic and Statistics (IBGE) of Brazil who conducted the survey.

\section{References}

1. Craike M, Young JA, Symons CM, Pain MD, Harvey JT, Eime RM, Payne WR. Trends in body image of adolescent females in metropolitan and non-metropolitan regions: a longitudinal study. BMC Public Health 2016; 16(1):1143.

2. Matias TS, Rolim MKSB, Kretzer FL, Schmoelz CP, Andrade A. Satisfação corporal associada a prática de atividade física na adolescência. Mot Rev Educ Fis 2010; 16(2):370-378.

3. Arigo D, Smyth JM. The benefits of expressive writing on sleep difficulty and appearance concerns for college women. Psychol Health 2012; 27(2):210-226.

4. Blashill AJ, Wilhelm S. Body image distortions, weight, and depression in adolescent boys: Longitudinal trajectories into adulthood. Psychol Men Masculinity 2014; 15(4):445-451.

5. Richard A, Rohrmann S, Lohse T, Eichholzer M. Is body weight dissatisfaction a predictor of depression independent of body mass index, sex and age? Results of a cross-sectional study. BMC Public Health 2016; 16(1):863.

6. Watkins ER. Constructive and unconstructive repetitive thought. Psychol Bull 2008; 134(2):163-206.

7. Duchesne M, Almeida PEM. Cognitive-behavioural therapy of eating disorders. Rev Bras Psiquiatr 2002, 24(Supl. 3):49-53.

8. Fredrickson J, Kremer P, Swinburn B, Silva-Sanigorski A, McCabe M. Biopsychosocial correlates of weight status perception in Australian adolescents. Body Image 2013; 10(4):552-557.

9. Pelegrini A, Coqueiro RS, Beck CC, Ghedin KD, Lopes AS, Petroski EL. Dissatisfaction with body image among adolescent students: association with socio-demographic factors and nutritional status. Cien Saude Colet 2014; 19(4):1201-1208.

10. Evans EH, Adamson AJ, Basterfield L, Le Couteur A, Reilly JK, Reilly JJ, Parkinson KN. Risk factors for eating disorder symptoms at 12 years of age: A 6-year longitudinal cohort study. Appetite 2016; 108:12-20.

11. Berg P, Paxton SJ, Keery H, Wall M, Guo J, Neumark-Sztainer D. Body dissatisfaction and body comparison with media images in males and females. Body Image 2007; 4(3):257-268.

12. Eisenberg ME, Neumark-Sztainer D, Paxton SJ. Fiveyear change in body satisfaction among adolescents. J Psychosom Res 2006; 61(4):521-527.

13. Neumark-Sztainer D, Paxton SJ, Hannan PJ, Haines J, Story M. Does body satisfaction matter? Five-year longitudinal associations between body satisfaction and health behaviors in adolescent females and males. J Adolesc Health 2006; 39(2):244-251.

14. Murray K, Rieger E, Byrne D. A longitudinal investigation of the mediating role of self-esteem and body importance in the relationship between stress and body dissatisfaction in adolescent females and males. Body Image 2013; 10(4):544-551.

15. Brown A, Dittmar H. Think "Thin" and Feel Bad: The Role of Appearance Schema Activation, Attention Level, and Thin-Ideal Internalization for Young Women's Responses to Ultra-Thin Media Ideals. J Soc Clin Psychol 2005; 24(8):1088-1113. 
16. Grabe S, Ward LM, Hyde JS. The role of the media in body image concerns among women: a meta-analysis of experimental and correlational studies. Psychol Bull 2008; 134(3):460-476.

17. Wong Y, Lin JS, Chang YJ. Body satisfaction, emotional intelligence, and the development of disturbed eating: a survey of Taiwanese students. Asia Pac J Clin Nutr 2014; 23(4):651-659.

18. Mellor D, Hucker A, Waterhouse M, binti Mamat NH, Xu X, Cochrane J, McCabe M, Ricciardelli L. A cross-cultural study investigating body features associated with male adolescents' body dissatisfaction in Australia, China, and Malaysia. Am J Mens Health 2014; 8(6):521-531.

19. Oliveira MM, Campos MO, Andreazzi MAR, Malta DC. Characteristics of the National Adolescent School-based Health Survey - PeNSE, Brazil. Epidemiol Serv Saude Rev Sist Unico Saude Bras 2017; 26(3):605-616.

20. Pan American Health Organization (PAHO). World Health Organization (WHO). GSHS General Documents [Internet]. [cited 2018 July 3]. Available from: https://www.paho.org/hq/index.php?option $=$ com docman\&task=cat_view\&gid=1956\&Itemid=2518\&l ang=en

21. Guedes DP, Lopes CC. Validação da versão brasileira do Youth Risk Behavior Survey 2007. Rev Saude Publica 2010; 44(5):840-850.

22. Brasil. Instituto Brasileiro de Geografia e Estatística (IBGE). Ministério da Saúde (MS). Questionário PeNSE 2015 [Internet]. [cited 2018 July 3]. Available from: https://biblioteca.ibge.gov.br/biblioteca-catalogo.html?id=54595\&view=detalhes

23. Silva KS, Lopes AS, Hoefelmann LP, Cabral LGA, De Bem MFL, Barros MVG, Nahas MV. Health risk behaviors Project (COMPAC) in youth of the Santa Catarina State, Brazil: ethics and methodological aspects. RBCDH 2013;15(1):1-15.

24. Forste R, Potter M, Erickson L. Sad and lonely: body dissatisfaction among adolescent girls. Int J Adolesc Med Health 2017; 31(2):pii.
25. Holsen I, Kraft P, Røysamb E. The relationship between body image and depressed mood in adolescence: A 5-year longitudinal panel study. J Health Psychol 2001; 6(6):613-627.

26. Latzer Y, Tzischinsky O, Spivak-Lavi Z, Chen I, Weinberger-Litman S. The Relationship between Disordered Eating Pathology, Sense of Coherence and Body Image among Adolescent Boys in Israel. Isr J Psychiatry Relat Sci 2018; 55(1):66-71.

27. Sharpe H, Patalay P, Choo T-H, Wall M, Mason SM, Goldschmidt AB, Neumark-Sztainer D. Bidirectional associations between body dissatisfaction and depressive symptoms from adolescence through early adulthood. Dev Psychopathol 2018; 30(4):1447-1458.

28. Lund HG, Reider BD, Whiting AB, Prichard JR. Sleep patterns and predictors of disturbed sleep in a large population of college students. J Adolesc Health 2010; 46(2):124-132.

29. Matthews KA, Hall MH, Cousins J, Lee L. Getting a Good Night's Sleep in Adolescence: Do Strategies for Coping With Stress Matter? Behav Sleep Med 2016; 14(4):367-377.

30. Capaldi Ii VF, Handwerger K, Richardson E, Stroud LR. Associations between sleep and cortisol responses to stress in children and adolescents: a pilot study. $B e$ hav Sleep Med 2005; 3(4):177-192.

Article submitted 27/02/2018

Approved 05/08/2018

Final version submitted 07/08/2018 